\title{
EVALUATION OF BI-DIRECTIONAL TURBINES USING THE TWO-SENSOR METHOD
}

\author{
K. Kaneuchi ${ }^{1 *}$, K. Nishimura ${ }^{1}$ \\ ${ }^{1}$ Osaka Gas CO., LTD, 6-19-9, Torishima, Konohana-ku, Osaka, Japan. \\ *e-mail:k-kaneuchi@osakagas.co.jp
}

Keywords: Bi-directional turbine, two-sensor method

\section{Introduction}

Various forms of thermal energy: solar heat, waste heat, and geothermal etc., can be converted to acoustic power utilizing thermo-acoustic phenomena. Acoustic power can be used for refrigeration and power generation. For power generation, linear alternators are typically used. However linear alternators are limited when it comes to cost and scalability. Kees de Blok proposed the use of a bi-directional turbine (BDT) which converts acoustic power into rotational energy [1]. His study determined that fluid density and frequency contributed to conversion efficiency. However, BDT behavior in thermoacoustic systems is not clear. The purpose of this study is to confirm the influence of a BDT on the sound field. Both the upstream and downstream sound fields were evaluated by two-sensor method.

\section{Experiment}

The BDT consists of a rotor with symmetric blades and two guide vanes (Figure 1). The rotor rotates in the same direction regardless of flow. Prototypes were made using a 3D-printer (Figure 2). Tim Kloprogge's document [2] was referred to when determining the blade shape. In this experiment, three types of turbines with different blade pitch (Figure 3) were evaluated.

The experiment consisted of two loudspeakers (FOSTEX, FW208N), polyvinyl chloride tubes and a BDT (Figure 4). A $40 \mathrm{~Hz}$ sine wave was generated from the source speaker; past the BDT we used the second speaker to eliminate reflections off the end of the tube. Pressure sensors (JTEKT, PD104K-30K) were placed in both the upstream and downstream of the BDT. Pressure, particle velocity, work flow, and impedance were evaluated using the two-sensor method.

A brushless motor (HADKER, A20-26M) was used as a power generator. The output of the generator was connected to a $2 \Omega$ resistor. With this setup, generated power and rotation speed were measured.

\section{Result}

Using the two-sensor method: pressure, particle velocity, work flow, impedance and phase difference between pressure and particle velocity were approximated (Figure 5). Electrical conversion efficiency of the BDT was evaluated using the difference in work flow across the BDT. Generated power was measured using a series circuit with the motor and resistor. Results for each turbine are shown in table 1. We determined that differences in blade number contribute to electrical conversion efficiency.

\section{Conclusions}

Sound fields around the BDT were evaluated using the two-sensor method. We determined that blade pitch contributes to electrical conversion efficiency from acoustic power. For 
practical use, further studies are required. For example, evaluation in a pressurized condition and an evaluation regarding blade shape.

\section{Acknowledgements}

We wish to thank Kees de Blok in Aster Thermoacoustics for his helpful discussions regarding the BDT and applications of thermoacoutics.

\section{References}

[1] Kees de BLOK, Pawel OWCZAREK, Maurice-Xavier FRANCOIS "Bi-directional turbines for converting acoustic wave power into electricity", 9th PAMIR International Conference, Riga,Latvia (2014) , 433-438

[2] Tim Kloprogge, "Turbine Design for Thermoacoustic Generator", Document of FACT foundation, FACT-5
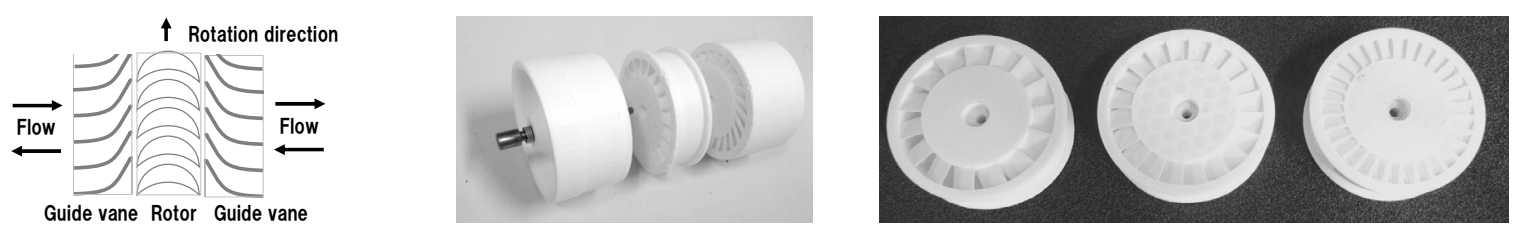

Figure 1: Conceptual diagram of BDT. Figure 2: Appearence of BDT.

Figure 3: Rotors of different pitch.

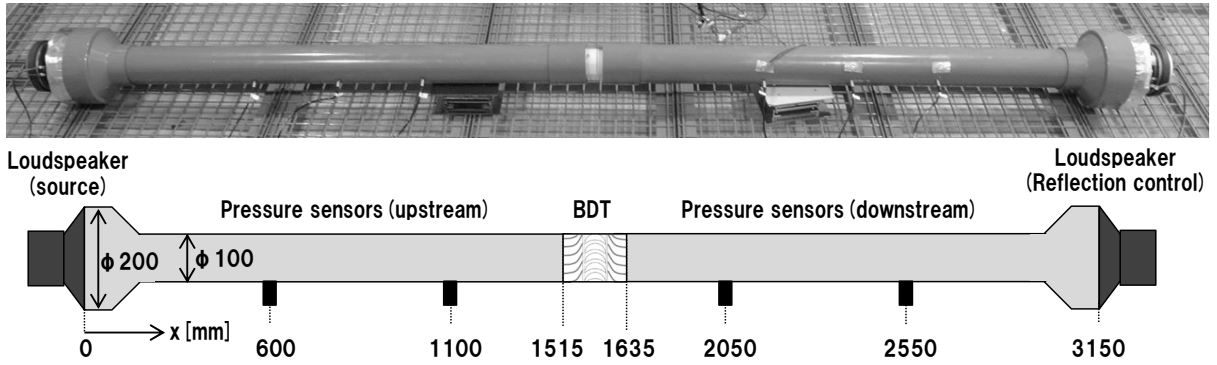

Figure 4: Photograph and cross-section of the experimental setup
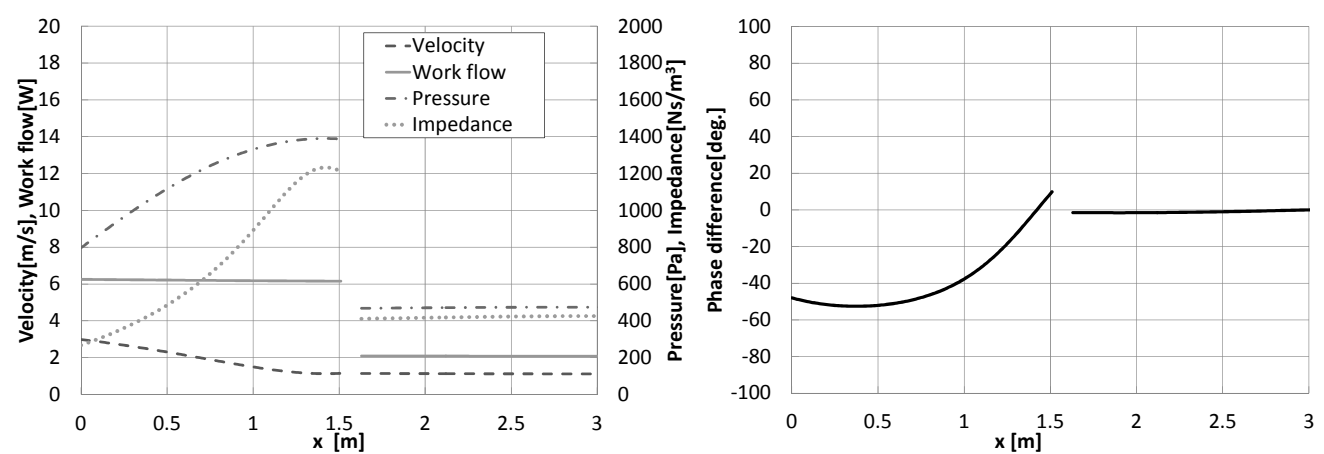

Figure 5: Pressure, particle velocity, work flow, impedance and phase difference approximated by two-sensor method.

Table 1: Results of our evaluation.

\begin{tabular}{|c|c|c|c|c|c|}
\hline \multicolumn{2}{|c|}{ Number of blades } & \multirow{2}{*}{$\begin{array}{l}\text { Rotation speed } \\
{[\text { rpm] }}\end{array}$} & \multirow{2}{*}{$\begin{array}{l}\text { Difference in Work flow } \\
\text { across the BDT[W] }\end{array}$} & \multirow{2}{*}{$\begin{array}{l}\text { Electric-generating } \\
\text { capacity }[\mathrm{W}]\end{array}$} & \multirow{2}{*}{$\begin{array}{c}\text { Acousitic-electric } \\
\text { conversion efficiency[\%] }\end{array}$} \\
\hline Rotor & Guide vane & & & & \\
\hline 15 & 12 & 2353 & 7.8 & 0.89 & 11.3 \\
\hline 20 & 16 & 2473 & 8.3 & 0.97 & 11.7 \\
\hline 30 & 24 & 2076 & 9.1 & 0.70 & 7.7 \\
\hline
\end{tabular}

